\title{
PENGARUH KOMPENSASI, KOMUNIKASI DAN STRESS KERJA TERHADAP PRESTASI KERJA KARYAWAN PADA PT CATUR PUTRA JAYA KOTA DEPOK - JAWA BARAT
}

\author{
Denok Sunarsi ${ }^{1)}$ \\ ${ }^{1)}$ dosen universitas pamulang, email : denoksunarsi@gmail.com
}

\section{ARTICLES \\ INFORMATION}

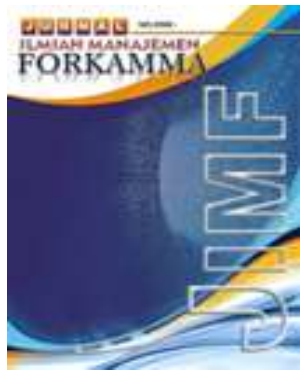

JURNAL ILMIAH MANAJEMEN FORKAMMA

\author{
Vol.1, No.2, Februari 2018 \\ Halaman : $113-127$ \\ (c) LPPM \& FORKAMMA
}

Prodi Magister Manajemen

UNVERSITAS PAMULANG

ISSN (online) : 2599-171X

ISSN (print) : :2598-9545

\section{Keyword :}

competence, communication, job stress, job performance

JEL. classification :

C33, G20, J53, L62

\section{Contact Author: \\ PRODI \\ MAGISTER MANAJEMEN \& FORKAMMA UNPAM \\ JL.Surya Kencana No.1 Pamulang \\ Tangerang Selatan - Banten \\ Telp. (021) 7412566, Fax (021) 7412491 \\ Email : \\ jurnalforkamma.unpam@gmail.com}

Tujuan penelitian ini untuk mengetahui seberapa besar pengaruh kompensasi, komunikasi dan stress kerja terhadap prestasi kerja karyawan pada PT Catur Putra Jaya kota Depok - Jawa Barat. Jenis penelitian merupakan penelitian kuantitatif dianalisis menggunakan statistik penulis menjadikan karyawan PT Catur Putra Jaya sebagai populasi totalnya berjumlah 210 karyawan. Adapun jumlah sampel diperoleh dari perhitungan Slovin dengan tingkat galat sebesar 10\% diperoleh hasil 67,7 , dibulatkan menjadi 68 responden. Analisis data menggunakan SPSS Versi 17. Teknik uji sampling menggunakan metode sensus dan teknik pengambilan data diantaranya uji validitas, uji reliabilitas, uji asumsi klasik dan uji regresi linear berganda serta uji hipotesis. Hasil penelitian menunjukan bahwa kompensasi, komunikasi dan stress kerja memiliki pengaruh yang positif dan signifikan terhadap prestasi kerja dan besarnya pengaruh kompensasi, komunikasi dan stress kerja terhadap prestasi kerja adalah $\mathrm{F}_{\text {nitung }} 32,846>\mathrm{F}_{\text {tabel }} 2,748$.

The purpose of this study is to determine how big the influence of compensation, communication and job stress on job performance of employees at PT Catur Putra Jaya Depok city - West Java. This type of research is quantitative research were analyzed using statistics, the author makes the employees of PT Catur Putra Jaya as the population there were a total of 210 employees. As for the number of samples obtained from the calculation Slovin with the level of error amounted to $10 \%$ of the obtained results to 67.7, rounded up to 68 respondents. Data analysis using SPSS Version 17. Mechanical test sampling using census method and data retrieval techniques include validity test, reliability test, classical assumption test and multiple linear regression test and test the hypothesis. The results of the study showed that compensation, communication and job stress have a positive and significant influence on job performance and the magnitude of the effect of compensation, communication and job stress on job performance is the $F$ count 32,846 > F table 2,748. 


\section{A. Pendahuluan}

Persaingan pasar sepeda motor saat ini sangat menarik, bahwa tahun ini adalah bukti perseteruan abadi antara Honda dan Yamaha. Meski pasar nasional disesaki Suzuki, Kawasaki, Kanzen dan beberapa pendatang baru dari India, tetapi mereka hanya kebagian kue tak lebih dari 10 persen dari pasar nasional. Sisanya, menjadi porsi Honda dan Yamaha. Selama 10 bulan terakhir di tahun 2009, Honda dan Yamaha mampu merebut 91,33\% pangsa pasar sepeda motor Indonesia.

Sepanjang 33 tahun sejarah persaingan sepeda motor di Tanah Air selalu didominasi Honda. Sebagai pelopor industri motor akarnya kuat menancap sejak 11 Juni 1971 dengan nama awal PT Federal Motor. Tipe motor pertama kali diproduksi adalah S $90 Z$ bermesin 4-tak 90cc. Sejak saat itu Honda langsung berjaya. Jumlah produksi tahun pertama 1.500 unit, melonjak menjadi 30 ribu di tahun berikutnya hingga mencatat produksi ke 20 juta tahun 2007.

Yamaha menyusul masuk ke Indonesia pada 6 Juli 1974. Varian yang diandalkan adalah motor yang menganut sistem 2 langkah. Namun kehadiran 'Samurai' Yamaha tak mampu menggoyang dominasi Honda.

Tapi, pada Maret 2007 semua mata terperanjat. Dominasi Honda rontok. Walau akhirnya Honda kembali merebut peran sebagai market leader. Tapi, ini terulang lagi di bulan Juli. Meski kembali direbut Honda di bulan berikutnya. Yamaha tidak menang, tapi sempat memimpin.

Dan puncaknya, semester pertama 2009, Yamaha benar-benar menohok. Total penjualan, Yamaha unggul hanya 4 ribuan unit dari Honda. Honda dan Yamaha saling susul-menyusul. Honda unggul pada bulan Januari, Februari, dan Maret. Sedangkan Yamaha pada April, Mei, Juni.

Hal ini membuat PT Astra Honda Motor berbenah. Strategi berubah. Manajemen pun dirombak. Pada Agustus, perubahan strategi bisnis dilakukan Honda dengan mulai menggenjot produksi skutik. Hasilnya, PT Astra Honda Motor (AHM) selaku ATPM Honda motor di Indonesia berhasil kembali memimpin pasar motor bulanan. Prestasi ini diteruskan merek berlambang sayap mengepak hingga bulan lalu dengan total penjualan 199.285 unit. Sementara itu, total penjualan Yamaha 188.604 unit (termasuk ekspor 700 unit).

Dari total penjualan yang dikukuhkan kedua merek sepanjang Januari hingga September, Honda kembali merebut posisi pemimpin dengan perolehan 1.899.184 unit. Adapun Yamaha harus puas dengan pencapaian 1.892.401 unit.

Berperang era kini, tak hanya brand besar yang diandalkan. Irit bahan bakar tak lagi jadi isu utama jualan. Tapi perlu kreatif dan kemasan promosi yang mengena. Dan itulah yang kini dilakukan Honda. PT Yamaha Motor Kencana Indonesia (YMKI) tak mau kalah. Promosi digenjot. Event digelar dari hulu sampai hilir. Segmentasi promosi dari anak-anak hingga kakek-kakek. Dari sepak bola sampai musik.

Honda adalah pelopor industri motor di Indonesia. Berdiri sejak 11 Juni 1971 dengan nama PT Federal Motor. Saat itu, PT Federal Motor hanya merakit, sedangkan komponennya diimpor dari Jepang dalam bentuk CKD (completely knock down).

Tipe motor pertama kali diproduksi adalah tipe bisnis, $S 90 Z$ bermesin 4-tak dengan kapasitas $90 \mathrm{cc}$. Di tahun pertama, jumlah produksi hanya 1.500 unit, namun melonjak menjadi sekitar 30 ribu pada tahun berikutnya dan terus berkembang hingga saat ini.

Dipicu kebijakan pemerintah dalam hal lokalisasi komponen otomotif, mendorong PT Federal motor memproduksi komponen Honda (2001) di dalam negeri melalui beberapa anak perusahaan. Di antaranya PT Honda Federal (1974) memproduksi komponen dasar motor seperti rangka, roda, knalpot dan sebagainya. PT Showa Manufacturing Indonesia (1979) khusus memproduksi peredam kejut, PT Honda Astra Engine Manufacturing (1984) memproduksi mesin motor serta PT Federal Izumi Mig. (1990) khusus piston. 
Seiring perkembangan kondisi ekonomi serta pasar motor, komposisi kepemilikan saham berubah. Tahun 2000 PT Federal Motor dan beberapa anak perusahaan dimerger menjadi PT Astra Honda Motor, yang komposisi kepemilikan sahamnya menjadi 50\% milik PT Astra Internasional Tbk dan 50\% milik Honda Motor Co. Japan.

Saat ini PT AHM memiliki tiga pabrik perakitan. Pertama di Sunter, Jakarta Utara. Kedua di Pegangsaan Dua, Kelapa Gading, serta ketiga yang sekaligus pabrik paling mutakhir berlokasi di kawasan MM 2100 Cikarang Barat, Bekasi. Pabrik ketiga ini merupakan fasilitas pabrik perakitan terbaru yang mulai beroperasi sejak 2005.

Dengan fasilitas ini PT AHM memiliki kapasitas produksi 3 juta unit motor pertahun. Salah satu puncak prestasi yang berhasil diraih PT Astra Honda Motor adalah pencapaian produksi ke 20 juta pada 2007. Dan pada Kamis, 15 Oktober 2009 ini sudah merayakan produksi ke-25 juta.

PT. Catur Putra Jaya merupakan bagian dari Catur Putra Group yang bergerak di bidang otomotif sebagai dealer resmi motor Honda yang tersebar di area Bekasi, Depok dan Bogor. Catur Putra Group berkomitmen untuk melayani dengan sepenuh hati dalam mewujudkan dan meningkatkan kepuasan dan loyalitas pelanggan melalui pengembangan seluruh sumberdaya secara berkesinambungan sehingga menjadi tolak ukur terpadu dealer sepeda motor Honda di Indonesia.

PT. Catur Putra Jaya memiliki budaya kerja yang kuat dalam semangat kebersamaan dan kekeluargaan untuk menyediakan kesempatan berkarya dalam mensyukuri kehidupan dan meningkatkan kesejahteraan bagi seluruh stakeholder.

PT. Catur Putra Jaya percaya bahwa setiap karyawan adalah aset berharga dan pemain kunci dalam membantu perusahaan mencapai visi dan misi menuju kesuksesan. Kami mencari profesional yang jujur, berintegritas, disiplin, bertanggung jawab dan termotivasi untuk maju. Saatnya bergabung dengan kami untuk menjadi bagian dari tim hebat kami.

Semangat kerja karyawan PT. Catur Putra seyogyanya di dukung oleh kompensasi yang baik dari perusahaan, komunikasi yang lancar tanpa hambatan baik sesama karyawan maupun dengan atasan langsung, dan menekan stress kerja karyawan sehingga dapat menghasilkan suatu prestasi kerja yang membanggakan baik untuk diri karyawan sendiri maupun untuk pengembangan perusahaan.

Menurut Hasibuan (2013 : 118) kompensasi adalah semua pendapatan yang berbentuk uang, barang langsung atau tidak langsung yang diterima karyawan sebagai imbalan atas jasa yang diberikan kepada perusahaan

Sementara menurut Redi Panuju (2000:4), pengertian komunikasi adalah sistem aliran yang menghubungkan, dan kinerja antar bagian didalam sebuah organisasi, yang menghasilkan adanya suatu sinergi.

Mangkunegara ( 2013:157 ), berpendapat bahwa stres kerja yaitu suatu perasaan tertekan yg dialami karyawan dalam menghadapi pekerjaan. Stres kerja ini tampak dari sindrom, antara lain emosi tidak stabil, perasaan tidak tenang, suka menyendiri, sulit tidur, merokok yg berlebihan, tidak bisa rileks, cemas, tegang, gugup, tekanan darah meningkat dan mengalami gangguan pencernaan.

Selanjutnya Mangkunegara (2013:157) berpendapat bahwa penyebab stres kerja antara lain, beban kerja yg dirasakan terlalu berat, waktu kerja yg mendesak, kualitas pengawasan yg rendah, iklim kerja yg tidak sehat, otoritas kerja yg tidak memadai yg berhubungan dengan tanggung jawab, konflik kerja, perbedaan antar karyawan dan pimpinan yg frustasi dalam kerja

Dan Handoko (2012:19) mengartikan prestasi kerja sebagai ungkapan kemampuan yang didasari oleh pengetahuan, sikap, keterampilan dan motivasi dalam menghasilkan sesuatu. Menurut Malayu S. Hasibuan (2013:94), menyatakan bahwa prestasi kerja adalah suatu hasil yang dicapai seseorang dalam melaksanakan tugas- 
tugas yang dibebankan kepadanya yang didasarkan atas kecakapan, pengalaman, dan kesungguhan serta waktu.

Dari gambaran singkat di atas, maka penulis tertarik untuk membahas lebih dalam mengenai sistem pemberian kompensasi, komunikasi dan stress kerja serta prestasi kerja, maka penulis tertarik mengangkat fenomena tersebut kedalam sebuah penelitian dengan judul "Pengaruh Kompensasi, Komunikasi dan Stress Kerja Terhadap Prestasi Kerja Karyawan Pada PT. Catur Putra Jaya, Depok - Jawa Barat."

\section{B. Perumusan Masalah}

Berdasarkan latar belakang yang telah diungkapkan di atas, maka rumusan masalah dalam penelitian ini adalah :

1. Bagaimana pengaruh kompensasi terhadap prestasi kerja ?

2. Bagaimana pengaruh komunikasi terhadap prestasi kerja ?

3. Bagaimana pengaruh stress kerja terhadap prestasi kerja ?

4. Seberapa besar pengaruh kompensasi, komunikasi dan stress kerja terhadap prestasi kerja secara simultan?

C. Kerangka Berpikir

Kerangka berfikir penelitian ini dapat digambarkan sebagai berikut

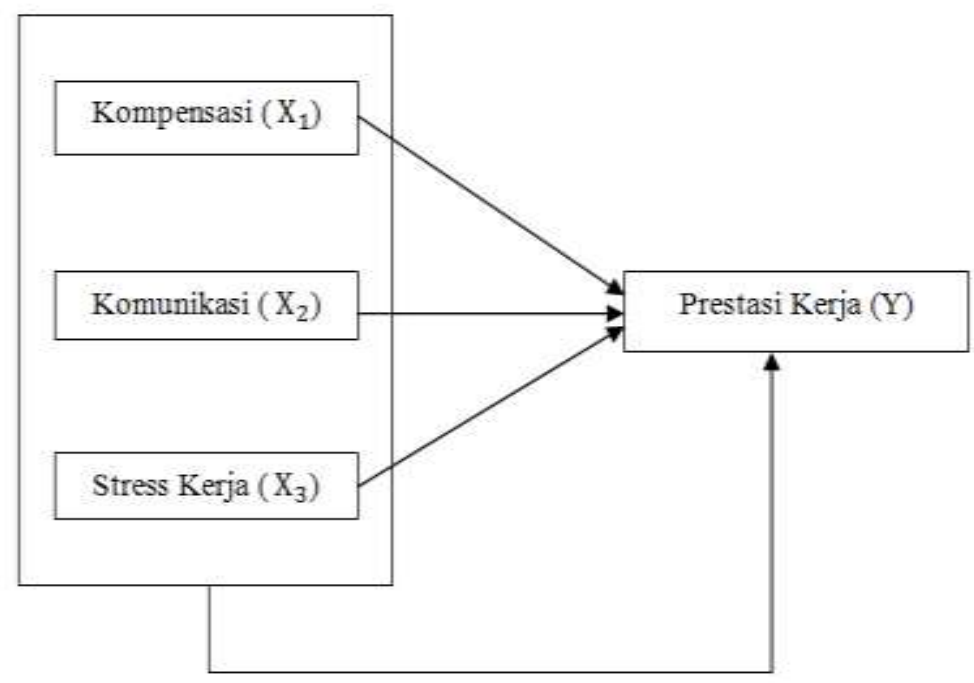

\section{Gambar 1.1}

Kerangka Berfikir

D. Landasan Teori

\section{Kompensasi}

Salah satu cara manajemen untuk meningkatkan prestasi kerja, motivasi, dan kepuasan kerja para karyawan adalah melalui kompensasi. Kompensasi karyawan merupakan elemen hubungan kerja yang sering menimbulkan masalah dalam hubungan industrial. Masalah kompensasi, khususnya upah, selalu menjadi perhatian manajemen organisasi, karyawan, dan pemerintah. Manajemen memperhitungkan upah karena merupakan bagian utama dari biaya produksi dan operasi, melukiskan 
kinerja karyawan yang harus dibayar, dan mempengaruhi kemampuannya untuk merekrut tenaga kerja dengan kualitas tertentu.

Menurut Umar (2007:16) kompensasi dapat didefinisikan sebagai sesuatu yang diterima karyawan sebagai balas jasa untuk kerja mereka. Sebelum kompensasi diberikan, terlebih dahulu dilakukan proses kompensasi. Kompensasi merupakan sebuah komponen penting dalam hubungannya dengan karyawan. Kompensasi sangat dipengaruhi faktor-faktor internal dan eksternal perusahaan yaitu suatu jaringan berbagai sub-proses untuk memberikan balas jasa kepada karyawan untuk pelaksanaan pekerjaan dan memotivasi mereka agar mencapai tingkat prestasi yang diinginkan. Imbalan atau balas jasa yang diterima karyawan dibagi atas dua macam, yaitu: imbalan yang bersifat finansial dan imbalan non-finansial yang tidak secara langsung berkaitan dengan prestasi kerja.

Menurut Mangkunegara (2013:83) Kompensasi merupakan suatu yang di pertimbangkan sebagai suatu yang sebanding.

\section{Komunikasi}

Sebagai makhluk sosial, komunikasi merupakan unsur penting dalam kehidupan manusia. Kegiatan komunikasi akan timbul jika seorang manusia mengadakan interaksi dengan manusia lain, jadi dapat dikatakan bahwa komunikasi timbul sebagai akibat dari adanya hubungan social. Pengertian tersebut mengandung arti bahwa komunikasi tidak dapat dipisahkan dari kehidupan umat manusia, baik sebagai individu maupun sebagai kelompok. Kata komunikasi atau communication dalam bahasa inggris berasal dari bahasa latin communis yang artinya "sama", communico, communication, atau communicare yang berarti "membuat sama" (to make common). Istilah pertama (communis) adalah istilah yang paling sering sebagai asal usul kata komunikasi, yang merupakan akar dari kata-kata Latin lainnya yang mirip.

Menurut Handoko (2012:272), komunikasi adalah proses pemindahan pengertian dalam bentuk gagasan atau informasi dari seseorang ke orang lain. Pemindahan pengertian tersebut melibatkan lebih dari sekedar kata-kata yang digunkan dalam percakapan, tetapi ekspresi wajah, intonasi, titik putus vocal dan sebagainya.

Menurut Andrew E. Sikula dalam Mangkunegara (2013:145), komunikasi adalah proses pemindahan suatu informasi, ide, pengertian dari seseorang kepada orang lain dengan harapan orang lain tersebut dapat menginterprestasikannya sesuai dengan tujuan yang dimaksud.

Menurut Norbert Weiner dalam Eko Harry Susanto (2010:13) komunikasi dinilai efektif, bila rangsangan yang disampaikan dan yang dimaksud oleh pengirim atau sumber, berkaitan erat dengan rangsangan yang ditangkap dan dipahami oleh penerima. Intinya, antara Sender (S) dan Receiver (R) ada kesamaan dalam memahami makna. Bila ini terjadi, maka komunikasi dapat dikatakan berjalan dengan baik.

Menurut Norbert Weiner dalam Eko Harry Susanto (2010: 2) umpan balik (feed back) sebagai unsur penting untuk mencapai komunikasi yang efektif. Umpan balik memberikan informasi tentang bagaimana komunikasi yang sudah dapat dilakukan dapat digunakan untuk menyesuaikan aktivitas berikutnya

Menurut Goyer (Eko Harry Susanto, 2010: 13), komunikasi dinilai efektif, bila rangsangan yang disampaikan dan dimaksud oleh pengirimnya ataupun sumber pesan, sejalan dengan rangsangan yang ditangkap dan dipahami oleh penerima pesan.

\section{Stress Kerja}

Menurut Mangkunegara (2013:157) Stres kerja merupakan perasaan tertekan yang dialami karyawan dalam menghadapi pekerjaan. Stres kerja ini tampak dari Sympton 
antara lain emosi tidak stabil, perasaan tidak tenang, suka menyendiri, sulit tidur, merokok yang berlebihan, cemas, tegang, gugup, tekanan darah meningkat, dan mengalami gangguan pencernaan.

Menurut Handoko (2012:200) Stress merupakan suatu kondisi ketegangan yang mempengaruhi emosi, proses berpikir, dan kondisi seseorang.

Menurut Hasibuan (2013:204), stress kerja yaitu suatu kondisi ketegangan yang mempengaruhi emosi, proses berfikir dan kondisi seseorang, orang yang stress menjadi nervous dan merasa kekuwatiran kronis

Rivai (2011:516) mengemukakan bahwa stress kerja adalah suatu kondoisi ketegangan yang menciptakan adanya ketidakseimbangan fisik dan psikis yang mempengaruhi emosi, proses berfikir dan kondisi seorang karyawan.

\section{Prestasi Kerja}

Penilaian prestasi kerja adalah proses mengevaluasi atau menilai prestasi kerja pegawai. Penilaian prestasi kerja yang dilaksanakan dengan baik, tertib dan benar, dapat membantu meningkatkan motivasi kerja dan sekaligus juga meningkatkan loyalitas pegawai.

Menurut Anwar Prabu Mangkunegara (2013:67) Penilaian prestasi kerja adalah hasil kerja secara kualitasdan kuantitas yang dicapai oleh seorang pegawai dalam melaksanakan tugasnya sesuai dengan tanggung jawab yang diberikan kepadanya.

Menurut Marihot Tua Efendi Hariandja (2005 : 101) Penilaian prestasi kerja adalah suatu evaluasi periodik dan sitematis tentang prestasi kerja/ jabatan (Job Performance) seorang tenaga kerja, termasuk potensi pengembangannya.

Menurut Kartini kartono (2008:8) Penilaian prestasi kerja merupakan keinginan untuk melaksanakan tugas atau pekerjaan yang sulit menguasai, memanipulasi atau mengorganisasi objek - objek fiscal.

\section{E. Metodologi Penelitian}

Jenis penelitian merupakan penelitian kuantitatif karena data penelitian berupa angka-angka yang nantinya akan dianalisis menggunakan statistik Penelitian ini bertujuan untuk mengetahui pengaruh kompensasi, komunikasi, dan stres kerja Terhadap prestasi kerja karyawan pada PT. Catur Putra Jaya.

\section{Populasi Dan Sampel}

Pada penelitian ini, penulis karyawan PT. Catur Putra Jaya sebagai populasi totalnya berjumlah 210 karyawan. Adapun jumlah sampel diperoleh dari perhitungan yang dikemukakan oleh Slovin dalam Husain (2003 : 146) dengan tingakat galat sebesar 10\% diperoleh hasil 67,7. Dibulatkan menjadi 68 responden .Dengan demikian, jumlah sampel yang digunakan sebagai responden dalam penelitian ini sebanyak 68 responden. Pengumpulan data yang dipergunakan dalam penelitian ini antara lain observasi, penyebaran kuisioner dan dokumentasi,. Dalam penelitian ini peneliti juga menggunakan kuesioner atau angket yang disebar pada responden (sampel penelitian) untuk mengetahui data tentang kompensasi, komunikasi dan stress kerja terhadap prestasi kerja karyawan. Dalam penilaian angket, digunakan skala likert dengan 5 alternatif jawaban yaitu sangat setuju, setuju, ragu-ragu, tidak setuju, sangat tidak setuju.

\section{Analisis Data}

Analisis data Analisis data yang digunakan dalam penelitian ini adalah uji validitas dan uji reliabilitas. Pengujian validitas menggunakan rumus korelasi pearson product moment, dengan ketentuan jika hiung $r>$ tabel $r$, berarti instrumen valid. Pengujian reliabilitas dalam penelitian ini menggunakan nilai Alpha Coanbach dengan ketentuan jika Alpha Croanbach ( hitung $r$ ) $>0,60$ berarti instrumen tersebut reliabel. Teknik 
analsis data antara lain uji asumsi klasik dan analisis regresi ganda. Uji asumsi klasik terdiri dari uji normalitas, uji multikolinearitas, uji heteroskedastisitas, uji autokorelasi.

\section{Uji Normalitas}

Data yang telah terkumpul harus diuji normalitasnya terlebih dahulu guna mengetahui apakah data penelitian berasal dari populasi yang sebarannya normal atau tidak. Pengujian normalitas dengan melihat grafik scatter plot.

\section{Uji Multikolinearitas}

Uji Multikolinearitas dilakukan untuk mengetahui ada tidaknya kemiripan yang dimiliki oleh satu variabel independent dengan variabel independen yang lain dalam satu model. Pengujian multikolinearitas dalam penelitian ini menngunakan VIF (Variance Inflation Factor), dengan ketentuan jika nilai tolerance $>0,1$ dan nilai VIF < 10 , maka data tidak maka data tidak mengalami multikolinearitas.

\section{Uji Heterokedastisitas}

Pengujian dilakukan untuk mengetahui apakah terjadi penyimpangan model karena gangguan variabel yang berbeda antar observasi ke observasi lain. Untuk mengetahui apakah terjadi heteroskedastisitas atau tidak, dapat dilihat pada gambar Scattreplot, jika pada gambar scatterplot tidak ada pola yang jelas serta titiktitik menyebar diatas dan dibawah angka 0 pada sumbu $Y$, maka tidak terjadi heterokedastisistas.

\section{Analisis Regresi Ganda}

Teknik analisis regresi ganda dipergunakan untuk mengetahui pengaruh kompensasi, komunikasi dan stress kerja terhadap prestasi kerja karyawan PT. Catur Putra Jaya. Dengan persamaan regresi $Y=a+b_{1} X_{1}+X_{2} b_{2}+X_{3} b_{3}$.

Teknik pengujian hipotesis menggunakan uji parsial dan uji simultan dengan teknik probabilitas, dengan cara membandingkan nilai probabilitas Sig dengan taraf signifikansi 0,05. Jika nilai probabilitas sig $<0,05$ maka signifikan.

\section{Koefisien Determinasi}

Pengujian koefisien determinasi bertujuan untuk mengetahui besarnya pengaruh antar variabel. Nilai koefisien determinasi menunjukkan presentase variasi nilai variabel dependen yang dapat dijelaskan oleh persamaan regresi yang dihasilkan.

\section{F. Hasil Penelitian dan Analisis}

\section{Uji Validitas dan reliabilitas}

\section{a. Uji Validitas}

Perhitungannya dengan cara membandingkan $r_{\text {hitung }}$ dengan $r_{\text {tabel }}$ dengan tingkat signifikan (kesalahaan) $5 \%$. Bila $r_{\text {hitung }}$ lebih besar dari $r_{\text {tabel }}$ nilai maka butir pertanyaan tersebut dikatakan valid. Dimana $r$ tabel diperoleh nilain 0,242, dengan jumlah sampel sebanyak 68. Maka hasil uji validitas intrument kuisioner no 1:

1) Variabel Komunikasi $\left(X_{1}\right)$ diperoleh $0,843>0,242$, sehingga $r$ hitung $>r$ tabel "valid" begitupun untuk intrumen no 2-5.

2) Variabel Kompensasi $\left(X_{2}\right)$ diperoleh $0,857>0,242$, sehingga $r$ hitung $>r$ tabel "valid" begitupun untuk intrumen no 2-5.

3) Variabel Stres Kerja $\left(X_{3}\right)$ diperoleh $0,843>0,242$, sehingga $r$ hitung $>r$ tabel "valid" begitupun untuk intrumen no 2-5.

4) Variabel Prestasi Kerja $(Y)$ diperoleh $0,801>0,242$, sehingga $r$ hitung $>r$ tabel "valid" begitupun untuk intrumen no 2-5.

\section{b. Ujl Reliabilitas}


Perhitungannya dengan cara membandingkan $r_{c a}$ dengan $r_{\text {tabel }}$ dengan tingkat signifikan (kesalahaan) 5\%. Butir kuesioner dikatakan reliabel (handal) bila nilai $r$

ca $>r_{\text {tabel }}$.

1) Variabel Komunikasi $\left(X_{1}\right)$ diperoleh $0,781>0,242$, sehingga $r$ ca $>r$ tabel "Reliabel".

2) Variabel Kompensasi $\left(X_{2}\right)$ diperoleh $0,725>0,242$, sehingga $r$ ca $>r_{\text {tabel }}$ "Reliabel".

3) Variabel Stres Kerja $\left(X_{3}\right)$ diperoleh $0,691>0,242$, sehingga $r$ ca $>r$ tabel "Reliabel".

4) Variabel Prestasi Kerja (Y) diperoleh $0,748>0,242$, sehingga $r$ ca $>r$ tabel "Reliabel.

2. Uji Asumsi Klasik

a. Uji Normalitas

Uji Normalitas bertujuan menguji apakah model regresi, variabel dependen dan independen keduanya memiliki distribusi normal atau tidak.Berikut gambar Normal Probability plot pada scatter plot:

Normal P-P Plot of Regression Standardized Residual

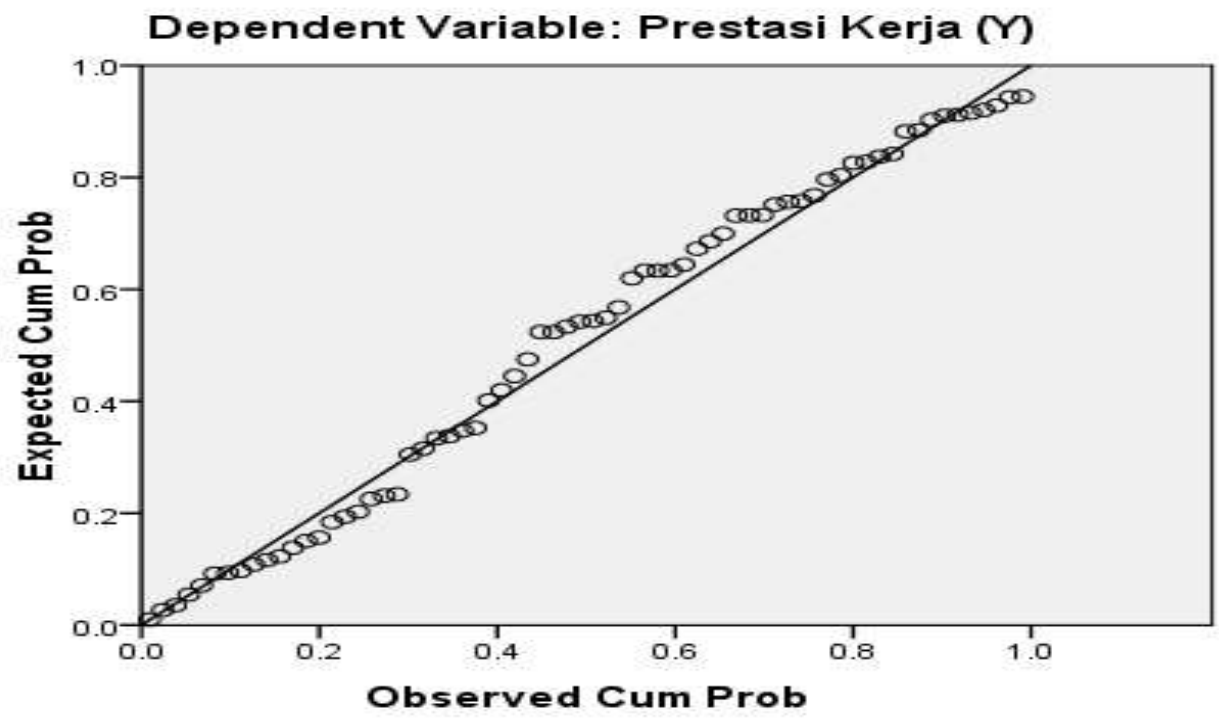

Gambar 4.1 Normal Probablity Plot

Gambar di atas menunjukan bahwa dari semua data yang ada berdistribusi normal, karena semua data menyebar membentuk garis lurus diagonal maka data tersebut memenuhi asumsi normal atau mengikuti garis normalitas.

b. Uji Heteroskedastisitas

Untuk menguji heteroskedastisitas dapat dilakukan dengan mengamati grafik scatterplot dengan pola titik-titik yang menyebar di atas dan di bawah sumbu Y. Berikut hasil pengolahan menggunakan program SPSS 
Scatterplot

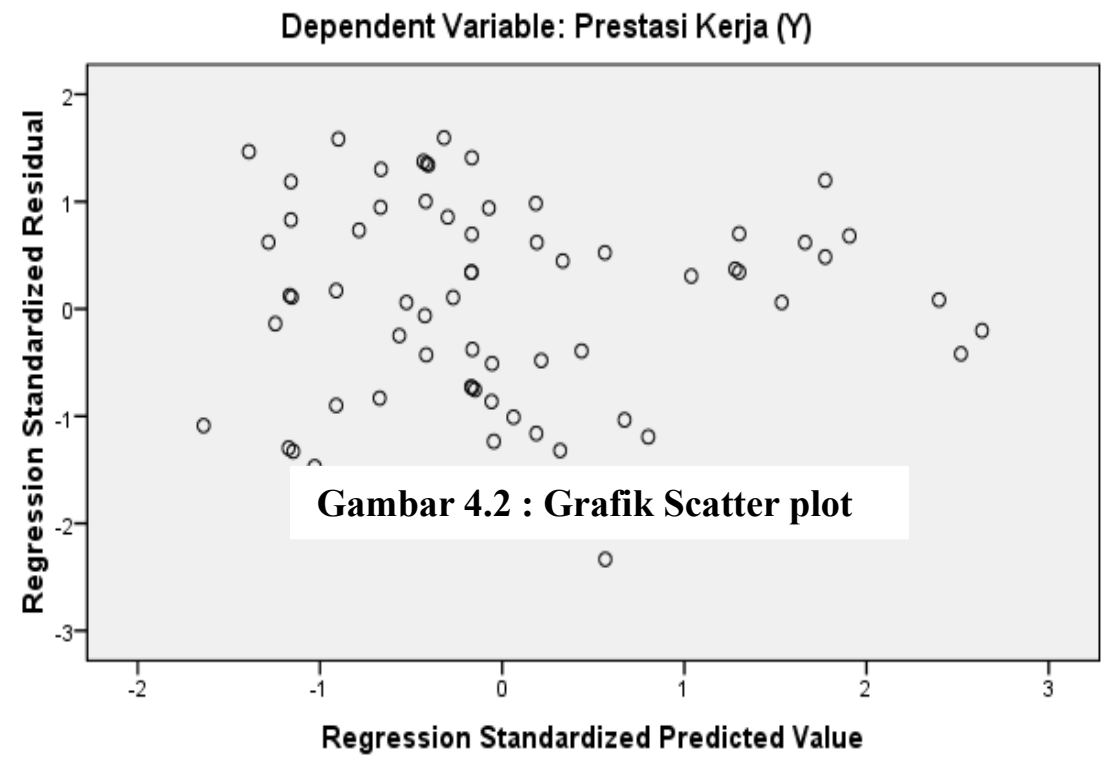

Scatterplot terlihat bahwa titik-titik menyebar secara acak serta tersebar baik di atas maupun dibawah angka nol pada sumbu Y. Hal ini dapat disimpulkan tidak terjadi heteroskedastisitas pada model regresi ini.

c. Uji Multikolinearitas

Pengujian ada tidaknya gejala multikolinieritas dilakukan dengan mempertahankan nilai matriks korelasi yang dihasilkan pada saat pengolahan data serta nilai VIF (Variance Inflation Factor) dan tolerance sebagai berikut:

Tabel 4.1 Uji Multikolinearitas

Coefficients $^{\mathrm{a}}$

\begin{tabular}{|c|c|c|c|c|c|c|}
\hline \multirow[b]{2}{*}{ Model } & & \multicolumn{2}{|c|}{ Unstandardized Coefficients } & \multirow{2}{*}{$\begin{array}{c}\text { Standardized } \\
\text { Coefficients } \\
\text { Beta }\end{array}$} & \multicolumn{2}{|c|}{ Collinearity Statistics } \\
\hline & & B & Std. Error & & Tolerance & VIF \\
\hline 1 & (Constant) & 2.894 & 1.459 & & & \\
\hline & Kompensasi (X1) & .426 & .174 & .402 & .227 & 4.401 \\
\hline & Komunikasi (X2) & .434 & .205 & .385 & .187 & 5.356 \\
\hline & Stress Kerja (X3) & .835 & .245 & .735 & .132 & 7.587 \\
\hline
\end{tabular}

a. Dependent Variable: Prestasi Kerja (Y)

Tabel 4.2 Rangkuman Uji Multikolinearitas

\begin{tabular}{|c|c|c|c|c|c|}
\hline Variabel & Tolerance & Kesimpulan & VIF & Kesimpulan & Keterangan \\
\cline { 1 - 5 } Kompensasi $\left(X_{1}\right)$ & 0,227 & $0,227>0,10$ & 4,401 & $4,401<10,00$ & \multirow{2}{*}{ Tidak Terjadi } \\
\cline { 1 - 5 } Komunikasi $\left(X_{2}\right)$ & 0,187 & $0,187>0,10$ & 5,356 & $5,356<10,00$ & Multikoliniearitas \\
\hline Stress Kerja $\left(X_{3}\right)$ & 0,132 & $0,132>0,10$ & 7,587 & $7,587<10,00$ & \\
\hline
\end{tabular}

Sumber: Analisis Penulis

\section{Analisis Regresi Linear}

\section{a. Regresi Linear Berganda}


Analisis regresi bertujuan untuk mengetahui hubungan antara variabel bebas dengan variabel terikat:

Tabel 4.3

Analisi Regresi Linear Berganda

Coefficients $^{\mathrm{a}}$

\begin{tabular}{|c|c|c|c|c|c|c|}
\hline \multirow[b]{2}{*}{ Model } & & \multicolumn{2}{|c|}{ Unstandardized Coefficients } & \multirow{2}{*}{$\begin{array}{c}\begin{array}{c}\text { Standardized } \\
\text { Coefficients }\end{array} \\
\text { Beta }\end{array}$} & \multicolumn{2}{|c|}{ Collinearity Statistics } \\
\hline & & B & Std. Error & & Tolerance & VIF \\
\hline 1 & (Constant) & 2.894 & 1.459 & & & \\
\hline & Kompensasi (X1) & .426 & .174 & .402 & .227 & 4.401 \\
\hline & Komunikasi (X2) & .434 & .205 & .385 & .187 & 5.356 \\
\hline & Stress Kerja (X3) & .835 & .245 & .735 & .132 & 7.587 \\
\hline
\end{tabular}

a. Dependent Variable: Prestasi Kerja (Y)

Sumber: Hasil Olah Data, 2017.

erdasarkan tabel di atas diperoleh persamaan regresi linear berganda sebagai berikut:

$$
Y=2,894+0,426 X_{1}+0,434 X_{2}+0,835 X_{3+} e
$$

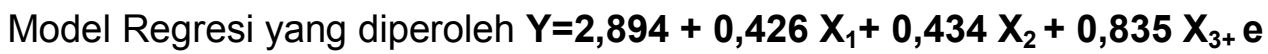

1. Konstanta ( $\alpha$ ) sebesar 2,894 menyatakan bahwa tanpa variabel Kompensasi, Komunikasi dan Stress Kerja besarnya nilai Prestasi Kerja tetap terbentuk sebesar 2,894.

2. Variabel Kompensasi $\left(\mathrm{x}_{1}\right)$ berpengaruh postif terhadap Prestasi Kerja (y) dengan nilai koefisiensi sebesar 0,426 , yang artinya jika variabel Kompensasi $\left(\mathrm{x}_{1}\right)$ meningkat satu satuan dengan asumsi variabel Komunikasi $\left(\mathrm{x}_{2}\right)$ dan Stress Kerja $\left(\mathrm{x}_{3}\right)$ tetap, maka Prestasi Kerja $(\mathrm{y})$ akan meningkat sebesar 0,426 , sehingga besar nya pengaruh Kompensasi terhadap Prestasi Kerja sebesar $42,6 \%$.

3. Variabel Komunikasi $\left(\mathrm{x}_{2}\right)$ berpengaruh positif terhadap Prestasi Kerja $(\mathrm{y})$ dengan nilai koefisien sebesar 0,434 yang artinya jika variabel Komunikasi $\left(x_{2}\right)$ meningkat satu satuan dengan asumsi variabel Kompensasi $\left(x_{1}\right)$ dan Stress Kerja $\left(\mathrm{x}_{3}\right)$ tetap, maka Prestasi Kerja $(\mathrm{y})$ akan meningkat sebesar 0,434 . Sehingga besar nya pengaruh Komunikasi terhadap Prestasi Kerja sebesar $43,3 \%$.

4. Variabel Stress Kerja $\left(x_{3}\right)$ berpengaruh positif terhadap Prestasi Kerja $(y)$ dengan nilai koefisien sebesar 0,835 yang artinya jika variabel Stress Kerja $\left(x_{3}\right)$ meningkat satu satuan dengan asumsi variabel Kompensasi $\left(x_{1}\right)$ dan Komunikasi $\left(\mathrm{x}_{2}\right)$ tetap, maka Prestasi Kerja $(\mathrm{y})$ akan meningkat sebesar 0,835 . Sehingga besar nya pengaruh Stress Kerja terhadap Prestasi Kerja sebesar $83,5 \%$. 
b. Korelasi Koefisien Determinasi

1. Koefisien Korelasi

Koefisien korelasi digunakan untuk melihat tingkat hubungan antra variabel Independen terhadap variabel dependen dimana dapat dilihat pada tabel berikut ini:

Tabel 4.4

Koefisien Korelasi

Model Summaryb

\begin{tabular}{|c|l|r|r|}
\hline Model & $\mathrm{R}$ & $\mathrm{R}$ Square & \multicolumn{1}{c|}{$\begin{array}{c}\text { Adjusted } \mathrm{R} \\
\text { Square }\end{array}$} \\
\hline 1 & $.779^{\mathrm{a}}$ & .606 & .588 \\
\hline
\end{tabular}

a. Predictors: (Constant), Stress Kerja (X3), Kompensasi (X1), Komunikasi (X2)

b. Dependent Variable: Prestasi Kerja (Y)

\section{Sumber: Hasil Olah Data Primer}

Dari tabel tersebut dipeoleh nilai $\mathrm{R}$ yaitu 0.779 diama Kompenasi, Komunikasi dan Stress Kerja memiliki Hubungan yang "kuat" terhadap Prestasi Kerja (y) karena 0.779 berada di antara 0.600 s/d 0.799.

2. Koefisien Determinasi

Koefisiensi determinasi $\left(R^{2}\right)$ bertujuan untuk mengetahui seberapa besar kemampuan variabel independen menjelaskan variabel dependen, dapat dilihat pada tabel berikut ini:

Tabel 4.5

Koefisien Determinasi

Model Summaryb

\begin{tabular}{|c|l|r|r|}
\hline Model & $\mathrm{R}$ & $\mathrm{R}$ Square & $\begin{array}{c}\text { Adjusted } \mathrm{R} \\
\text { Square }\end{array}$ \\
\hline 1 & $.779^{\mathrm{a}}$ & .606 & .588 \\
\hline
\end{tabular}

a. Predictors: (Constant), Stress Kerja (X3), Kompensasi (X1), Komunikasi (X2)

b. Dependent Variable: Prestasi Kerja (Y)

\section{Sumber: Hasil Olah Data Primer}

Hasil uji koefisien determinasi dilihat dari nialai ( $R$ Square) yang diperoleh sebesar 0,606. Hal ini berarti 60,6\% Prestasi Kerja dipengaruhi oleh variabel Kompensasi, Komunikasi dan Stress Kerja sedangkan sisanya 39,4\% Prestasi Kerja dipengaruhi oleh variabel-variabel lain yang tidak diteliti seperti Motivasi dan Kepemimpinan. 


\section{Uji Hipotesis}

a. Uji T

Selanjutnya untuk mengetahui apakah Kompensasi, Komunikasi dan Stress Kerja mempunyai pengaruh yang signifikan terhadap Prestasi Kerja maka perlu dilakukan uji signifikansi dengan menggunakan uji statistik (uji t) dengan menggunakan taraf siginifikansi sebsar $5 \%(0,05)$ dan derajat kebebasan $(\mathrm{dk})$ korelasi dengan rumus: $\mathrm{dk}=\mathrm{n}-\mathrm{k}-1$, dimana $n$ adalah jumlah responden, dan $k$ adalah jumlah variabel yang diteliti. Dimana $t$ tabel diperoleh:

Tabel 4.6

Hasil Uji T

Coefficients $^{\mathrm{a}}$

\begin{tabular}{|c|c|c|c|c|c|c|}
\hline \multirow[b]{2}{*}{ Model } & & \multicolumn{2}{|c|}{ Unstandardized Coefficients } & \multirow{2}{*}{$\begin{array}{c}\begin{array}{c}\text { Standardized } \\
\text { Coefficients }\end{array} \\
\text { Beta }\end{array}$} & \multirow[b]{2}{*}{$t$} & \multirow[b]{2}{*}{ Sig. } \\
\hline & & $B$ & Std. Error & & & \\
\hline 1 & (Constant) & 2.894 & 1.459 & & 1.983 & .042 \\
\hline & Kompensasi (X1) & .426 & .174 & .402 & 2.445 & .017 \\
\hline & Komunikasi (X2) & .434 & .205 & .385 & 2.412 & .038 \\
\hline & Stress Kerja (X3) & .835 & .245 & .735 & 3.403 & .001 \\
\hline
\end{tabular}

a. Dependent Variable: Prestasi Kerja (Y)

\section{Sumber: Hasil Olah Data Primer}

\section{1) Pengujian Hipotesis Pertama}

Dari tabel diatas dapat dilihat bahwa variabel Kompensasi diperoleh signifikansi $\mathrm{t}$ lebih kecil dari 0,05 $(0,017<0,05)$ dan $\mathrm{t}$ nitung 2,445 $>\mathrm{t}$ tabel sebesar 2,387 $(2,445>2,387)$ atau berarti $\mathrm{H}_{01}$ ditolak dan $\mathrm{H}_{\mathrm{a} 1}$ diterima, hal ini menunjukan bahwa terdapat pengaruh yang signifikan dari Kompensasi terhadap Prestasi Kerja.

2) Pengujian Hipotesis Kedua

Dari tabel diatas dapat dilihat bahwa variabel Komunikasidiperoleh signifikansi $\mathrm{t}$ lebih kecil dari 0,05 $(0,038<0,05)$ dan $\mathrm{t}_{\text {hitung }} 2,412>\mathrm{t}$ tabel sebesar 2,387 $(2,415>2,387)$ atau berarti $\mathrm{H}_{02}$ ditolak dan $\mathrm{H}_{\mathrm{a} 2}$ diterima, hal ini menunjukan bahwa terdapat pengaruh yang signifikan dari Komunikasi terhadap Prestasi Kerja.

3) Pengujian Hipotesis Ketiga

Dari tabel diatas dapat dilihat bahwa variabel Stress Kerjadiperoleh signifikansi $\mathrm{t}$ lebih kecil dari 0,05 $(0,001<0,05)$ dan $\mathrm{t}$ hitung $3,403>\mathrm{t}$ tabel sebesar 2,387 $(3,403>2,387)$ atau berarti $\mathrm{H}_{03}$ ditolak dan $\mathrm{H}_{\mathrm{a} 3}$ diterima, hal ini menunjukan bahwa terdapat pengaruh yang signifikan dari Stress Kerja terhadap Prestasi Kerja.

\section{b. Uji F}

Untuk menguji pengaruh Kompensasi, Komunikasi dan Stress Kerja secara bersama-sama terhadap Prestasi Kerja, dapat digunakan uji statistik F (uji F), dengan menggunakan taraf signifikansi $5 \%(0,05)$. 
Tabel 4.7

Hasil Uji F

ANOVA $^{b}$

\begin{tabular}{|c|c|c|c|c|c|c|}
\hline Model & & $\begin{array}{l}\text { Sum of } \\
\text { Squares }\end{array}$ & $\mathrm{df}$ & Mean Square & $F$ & Sig. \\
\hline \multirow[t]{3}{*}{1} & Regression & 773.606 & 3 & 257.869 & 32.846 & $.000^{\mathrm{a}}$ \\
\hline & Residual & 502.453 & 64 & 7.851 & & \\
\hline & Total & 1276.059 & 67 & & & \\
\hline
\end{tabular}

a. Predictors: (Constant), Stress Kerja (X3), Kompensasi (X1), Komunikasi (X2)

b. Dependent Variable: Prestasi Kerja $(Y)$

Sumber: Hasil Olah Data Primer

Dari hasil uji anova pada tabel diatas dapat diperoleh signifikansi $0,000<0,05$ dan $\mathrm{F}$ hitung $32,846>\mathrm{F}$ tabel 2,748 berarti $\mathrm{H}_{04}$ ditolak dan $\mathrm{H}_{a 4}$ diterima, Kompensasi, Komunikasi dan Stress Kerja Berpengaruh Positif dan Signifikan Terhadap Prestasi Kerja.

\section{G. Pembahasan Hasil Penelitian}

\section{Variabel Kompensasi}

a. Hasil analisis deskripstif menunjukan bahwa kompensasi di PT Catur Putra Jaya dinilai cukup baik di mana mayoritas responden menyatakan jawaban Ragu-ragu $34,7 \%$, maka dari itu kompensasi yang di berikan oleh PT Catur Putra Jaya harus ditingkatkan baik kompensasi materi atau non materi.

b. Berdarkan hasil uji validitas maka item kuisioner no $1 r_{\text {hitung }}(0,843)>r_{\text {tabel }}(0,242)$ berarti butir pertanyaan no.1 variabel Kompensasi $\left(\mathrm{X}_{1}\right)$ dinyatakan Valid.

c. Berdarkan hasil uji reliabilitas maka item kuisioner $r_{c a}(0,781)>r_{\text {tabel }}(0,242)$ dengan ketentuan $\alpha=5 \%$ maka varians butir item variable Kompensasi $\left(X_{1}\right)$ dapat dinyatakan Reliabel.

d. Hasil uji parsial diperoleh dari tabel 4.6 dapat dilihat bahwa variabel Kompensasi diperoleh signifikansi t lebih kecil dari 0,05 $(0,017<0,05)$ dan $\mathrm{t}_{\text {hitung }} 2,445>\mathrm{t}_{\text {tabel }}$ sebesar 2,387 $(2,445>2,387)$ atau berarti $\mathrm{H}_{01}$ ditolak dan $\mathrm{H}_{\mathrm{a} 1}$ diterima, hal ini menunjukan bahwa terdapat pengaruh yang signifikan dari Kompensasi terhadap Prestasi Kerja.

\section{Variabel Komunikasi}

a. Hasil analisis deskripstif menunjukan bahwa komunikasi di PT Catur Putra Jaya dinilai baik di mana mayoritas responden menyatakan jawaban Setuju sebanyak $35,6 \%$, maka dari itu proses komunikasi yang dilakukan oleh pimpinan terhadap bawahanya atau sebaliknya sudah berjalan dengan baik.

b. Berdarkan hasil uji validitas maka item kuisioner no $1 r_{\text {hitung }}(0,857)>r_{\text {tabel }}(0,242)$ berarti butir pertanyaan no.1 variabel Komunikas $\left(\mathrm{X}_{2}\right)$ dinyatakan Valid.

c. Berdarkan hasil uji reliabilitas maka item kuisioner $r_{c a}(0,725)>r_{\text {tabel }}(0,242)$ dengan ketentuan $\alpha=5 \%$ maka varians butir item variable Komunikasi $\left(X_{2}\right)$ dapat dinyatakan Reliabel.

d. Hasil uji parsial diperoleh dari tabel 4.6 dapat dilihat bahwa variabel Komunikasi diperoleh signifikansi $\mathrm{t}$ lebih kecil dari 0,05 $(0,038<0,05)$ dan $\mathrm{t}_{\text {hitung }} 2,412>\mathrm{t}_{\text {tabel }}$ sebesar 2,387 $(2,415>2,387)$ atau berarti $\mathrm{H}_{02}$ ditolak dan $\mathrm{H}_{\mathrm{a} 2}$ diterima, hal ini menunjukan bahwa terdapat pengaruh yang signifikan dari Komunikasi terhadap Prestasi Kerja. 


\section{Variabel Stress Kerja}

a. Hasil analisis deskripstif menunjukan bahwa stress kerja di PT Catur Putra Jaya dinilai sudah baik di mana mayoritas responden menyatakan jawaban Setuju $32,1 \%$, dimana pekerjaan yang diberikan atau dijalankan oleh karyawan PT Catur Putra Jaya sudah berjalan dengan baik dan tanpa ada tekanan berlebihan yang dapat menimbulkan strss kerja karyawan nya.

b. Berdarkan hasil uji validitas maka item kuisioner no $1 r_{\text {hitung }}(0,843)>r_{\text {tabel }}(0,242)$ berarti butir pertanyaan no.1 variabel Stress Kerja $\left(X_{3}\right)$ dinyatakan Valid.

c. Berdarkan hasil uji reliabilitas maka item kuisioner $r_{c a}(0,691)>r_{\text {tabel }}(0,242)$ dengan ketentuan $\alpha=5 \%$ maka varians butir item variable Stretss Kerja $\left(X_{3}\right)$ dapat dinyatakan Reliabel.

d. Hasil uji parsial diperoleh dari tabel 4.6 dapat dilihat bahwa variabel Stress Kerjadiperoleh signifikansi $t$ lebih kecil dari 0,05 $(0,001<0,05)$ dan $t_{\text {hitung }} 3,403>$ $\mathrm{t}_{\text {tabel }}$ sebesar 2,387 $(3,403>2,387)$ atau berarti $\mathrm{H}_{03}$ ditolak dan $\mathrm{H}_{\mathrm{a} 3}$ diterima, hal ini menunjukan bahwa terdapat pengaruh yang signifikan dari Stress Kerja terhadap Prestasi Kerja.

\section{Variabel Prestasi Kerja}

a. Hasil analisis deskripstif menunjukan bahwa prestasi kerja di PT Catur Putra Jaya dinilai cukup baik di mana mayoritas responden menyatakan jawaban Ragu-ragu 30,9\%, dimana

karyawan masih ragu terhadap prestasi kerja didalam menyelesaikan pekerjaanya maka dari itu di harapkan agar PT Catu Putra Jaya dapat membantu meningkatkan motivasi kerja dan sekaligus juga meningkatkan loyalitas karyawan.

b. Berdarkan hasil uji validitas maka item kuisioner no $1 r_{\text {hitung }}(0,801)>r_{\text {tabel }}(0,242)$ berarti butir pertanyaan no.1 variabel Prestasi Kerja (y) dinyatakan Valid.

c. Berdarkan hasil uji reliabilitas maka item kuisioner $r_{c a}(0,748)>r_{\text {tabel }}(0,242)$ dengan ketentuan $\alpha=5 \%$ maka varians butir item variable Prestasi Kerja $(y)$ dapat dinyatakan Reliabel.

d. Hasil uji simultan diperoleh dari tabel 4.7 Dapat dilihasi dari hasil uji anova pada tabel diatas dapat diperoleh signifikansi $0,000<0,05$ dan $\mathrm{F}_{\text {hitung }} 32,846>\mathrm{F}_{\text {tabel }}$ 2,748 berarti $\mathrm{H}_{04}$ ditolak dan $\mathrm{H}_{a 4}$ diterima, Kompensasi, Komunikasi dan Stress Kerja Berpengaruh Positif dan Signifikan Terhadap Prestasi Kerja.

\section{H. Kesimpulan}

1) Kompensasi memiliki pengaruh yang positif dan signifikan terhadap prestasi kerja karyawan PT Catur Putra Jaya hal ini dilihat dari hasil uji hipotesis diperoleh nilai $t$ hitung $2,445>\mathrm{t}_{\text {tabel }}$ sebesar 2,387 $(2,445>2,387)$.

2) Komunikasi memiliki memiliki pengaruh yang positif dan signifikan terhadap prestasi kerja karyawan PT Catur Putra Jaya hal ini dilihat dari hasil uji hipotesis diperoleh nilai dan $\mathrm{t}_{\text {hitung }} 2,412>\mathrm{t}_{\text {tabel }}$ Sebesar 2,387 (2,415 > 2,387).

3) Stress kerja memiliki pengaruh yang positif dan signifikan terhada prestasi kerja karyawan PT Catur Putra Jaya, hal ini dilihat dari $\mathrm{t}_{\text {hitung }} 3,403>\mathrm{t}_{\text {tabel }}$ sebesar 2,387 $(3,403>2,387)$.

4) Besarnya pengaruh Kompensasi, Komunikasi dan Stress Kerja terhadap Prestasi Kerja Karyawan PT Catur Putra Jaya sebesar 32,864 hal ini dilihat dari hasil uji $\mathrm{f}$ dimana diperoleh nilai $\mathrm{F}_{\text {hitung }} 32,846>\mathrm{F}_{\text {tabel }} 2,748$. 


\section{Daftar Pustaka}

\section{Buku}

Cangara, Hafied. 2014.Pengantar Ilmu Komunikasi. Jakarta: Rajagrafindo Persada Handoko, T. Hani. 2012. Manajemen Edisi 2. Yogyakarta: BPFE.

Hasibuan, Melayu. 2013. Manajemen Sumber Daya Manusia Edisi Revisi. Jakarta: Bumi Aksara.

Kartono Kartini 2008. Manajemen Sumber Daya Manusia. Jakarta: Grafindo

Mangkunegara, A. Prabu. 2013. Manajemen Sumber Daya Manusia. Bandung: PT. Remaja Rosdakarya

Marihot Tua Efendi Hariandja. 2005. Manajemen Sumber Daya Manusia. Jakarta : PT. Grasindo

Panuju, Redi. 2000. Komunikasi Bisnis. Jakarta: PT. Gramedia Pustaka Utama

Priansa, Doni Juni. 2014. Perencanaan dan Pengembangan Sumber Daya Manusia. Bandung: Alfabeta

Priyatno, Duwi. 2014. Paham Analisis Statistik Data Dengan SPSS. Yogyakarta : MediaKom.

Purwanto, Djoko. 2014. Komunikasi Bisnis Edisi 4. Jakarta: Erlangga

Rivai, Veitzhal. 2011. Manajemen Sumber Daya Manusia Untuk Perusahaan Edisi ke-2. Jakarta: PT. Raja Grafindo

Sugiyono. 2014. Metode Penelitian Kuantitatif dan Kualitatif $R$ \& $D$ Cetakkan Ke22 Bandung :Alfabeta

Suranto. 2011. Komunikasi Interpersonal. Yogyakarta : Graha ilmu

Susanto, Eko Harry.2010. Komunikasi manusia: Esensi dan Aplikasi Dalam Dinamika Sosial Ekonomi Politik. Jakarta: Mitra Wacana Media

Umar, Husain, 2007. Strategi Manajemen In Action. Jakarta: Gramedia Pustaka Utama

\section{Internet}

https://gadingmahendradata.wordpress.com/2009/12/01/pertarungan-honda-vsyamaha-dalam-pasar-sepeda-motor-nasional/

http://caturputrajaya.com/. 